\title{
On the New Method of Determining the Activities in Molten Alloys-The Touch Instant Electromotive Force Method*
}

\author{
By Kazuhisa Okajima** and Hiroshi Sakao**
}

\begin{abstract}
The present study was made of a new method by which the activities can be measured without regard to the substitution reaction in the cell. By this method, it is possible to measure the activities of an extremely dilute solution and also the activities of more noble components in a binary molten alloy which cannot be measured by a usual method. In the measurements, special attention was paid to minimize hum in the synchroscope. It was found that the activities of both components in the binary alloy are measured with good accuracy.
\end{abstract}

(Received July 3, 1967)

\section{Introduction}

The activities in molten alloys have been measured by a large number of investigators ${ }^{(1)}$. In particular, concentration cells having liquid electrodes and electrolytes have been used extensively in determining the activities of components of molten alloys. Important progress has been made, but unfortunately, the determinations of the activities have been restricted to the components of less noble metals, and other components had to depend upon calculation using activities of noble

* The greater part of this paper was published in the Journal of the Japan Institute of Metals, 31 (1957), 537.

** Department of Iron and Steel Engineering, Faculty of Engineering, Nagoya University, Nagoya, Japan.

(1) R. Hultgren, R. L. Orr, P. D. Anderson and K. K. Kelley: Selected Values of Thermodynamic Properties of Metals and Alloys, John Wiley and Sons, New York, (1963). components. Besides, there has been a limit in the determinations in extremely dilute solutions of less noble components because of the substitution reaction between electrolyte and alloy electrode, and some systems were found to be difficult to measure because of the small difference in electrolytic solution ten$\operatorname{sion}^{(2)}$.

The present study was made in an attempt to develop a new method by which the activities can be measured without regard to the substitution reaction in the cell. It is thus possible to measure the activities in extremely dilute solutions and also the activities of more noble components whose measurements have been difficult up to now. Accordingly, this method is found to serve as an important means for the inves-

(2) H. A. Laitinen and C. H. Liu : J. Amer. Chem. Soc., 80 (1958), 1015.

1968 Vol. 9 
tigation on the dilute solutions, e.g., Henry's law constant, interaction parameters, etc., and also for measuring the activities of all components in molten alloys. An extensive use to the field of kinetics may also be expected in the future.

This report describes in detail the new method, called the touch instant electromotive force method, for determining the activities of the molten alloys.

\section{Principle of the Touch Instant Electromotive Force Method}

If the components of alloys are denoted by $A$ and $B$, and the less noble component is $B$, the electrochemical cell by a usual method can be represented as follows :

$$
A-B\left|B^{+n}\right| \boldsymbol{B}
$$

where $n$ represents the valency of ion.

In this cell,

$$
A+B^{+n}=B+A^{+n} .
$$

The reaction (2) extremely inclines toward the left side, so that the substitution reaction between $A-B$ alloy and $B$ in the electrolyte can nearly be ignored and the electromotive force $E$ obtained from this cell gives the activity of component $B$ by virtue of the equation

$$
n E F=-R T \ln a_{B}
$$

In the activity measurements of component $A$ by this new method, the constitution of the cell is the same as the one mentioned above. Now, reversing the cell form (1) as shown in the following :

$$
B-A\left|A^{+n}\right| A \text {. }
$$

In this case, the reaction brings about changes in composition of both electrolyte and electrode in the vicinity of the interface and can add a non-reversible component to the potential of the cell. However, if the electromotive force between pure metal and alloy electrodes can be measured immediately prior to the reaction at the interface, the cell condition in this moment may be considered to be the same as the cell (1) which has no tendency toward the reaction. Consequently,

$$
n E F=-R T \ln a_{A} .
$$

From the electromotive force measurements, the activity of component $A$ may be obtained by virtue of Eq. (5).

This method goes through the steps that both electrodes are separated from the electrolyte at the start and then at a desired temperature the electromotive force is measured as soon as the electrolyte is touched with both electrodes.

Therefore, an apparatus is needed by which the electromotive force can be measured at a speed beyond the rate of reaction between electrolyte and alloy electrode, as soon as the electrolyte comes in contact with the electrodes. For this purpose, it is required to use a cathod ray oscillograph with very small time constant.

\section{Experimental Apparatus}

Arrangement of the apparatus employed in this experiment is indicated in Fig. 1. The furnace used

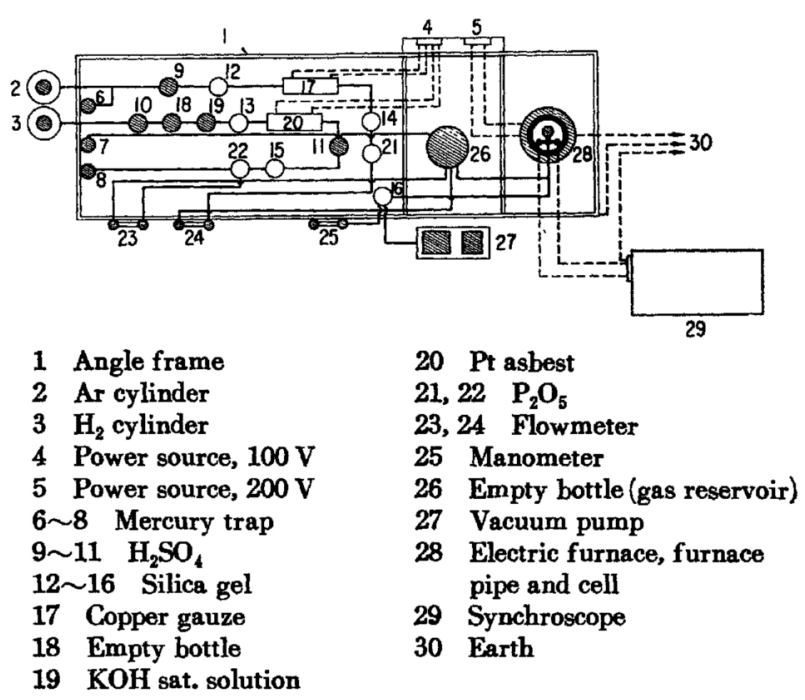

Fig. 1 Experimental apparatus.

for the measurements is a nichrome winding vertical furnace in which a stainless pipe is inserted in the center to make the temperature distribution uniform as well as to prevent hum in the synchroscope. The distribution of temperature was $\pm 0.5^{\circ} \mathrm{C}$ in the range of $5 \mathrm{~cm}$ at the middle part. Temperature measurements were carried out with the alumel-chromel thermocouple.

A gas mixture of argon and hydrogen was employed as an protective atmosphere in the cell. Argon gas was purified by passing through sulfuric acid, silica gel, copper gauze $\left(450^{\circ} \mathrm{C}\right)$, silica gel and phosphorous pentaoxide, while hydrogen gas was purified by sulfuric acide, $\mathrm{KOH}$ saturated solution, silica gel, $\mathrm{Pt}$ asbest $\left(300^{\circ} \mathrm{C}\right)$, sulfuric acid, silica gel and phosphorous pentaoxide. Then their gases, mixed by controlling the flow rate, were introduced into the cell. The flow rate of argon gas was about $300 \mathrm{cc} / \mathrm{min}$ and in the argon gas the hydrogen gas was mixed to amount to 5 to 10 percent.

Two types of cell design are illustrated in Figs. 2 and 3. Cell containers were made of the first-class hard glass; in the A-type cell, the pure metal and alloy electrodes were separated from the electrolyte by inserting the glass enclosure and in the B-type cell, the H-type tube having both electrodes was immersed in the electrolyte.

The lead wire was tungsten of dia. $0.8 \mathrm{~mm}$, in which a porcelain sheath was inserted for isolation. Adequate precaution was taken to avoid hum by using a carbon film resistance of 100 or $10 \mathrm{~K} \Omega$. A stainless rod was employed for breaking the electrolyte outlet (or inlet) in the cell.

In the present study in which the zinc-tin system was taken up as an example, metals and chlorides used 
were highest grade reagents. The electrolyte consisted of a molten mixture ôf 58 mole percent $\mathrm{LiCl}, 42$ mole percent $\mathrm{KCl}$ and small amounts of $\mathrm{SnCl}_{2}$ or $\mathrm{ZnCl}_{2}$ added.

SS-5302 Synchroscope (Sensitivity max. $1 \mathrm{mV}$,

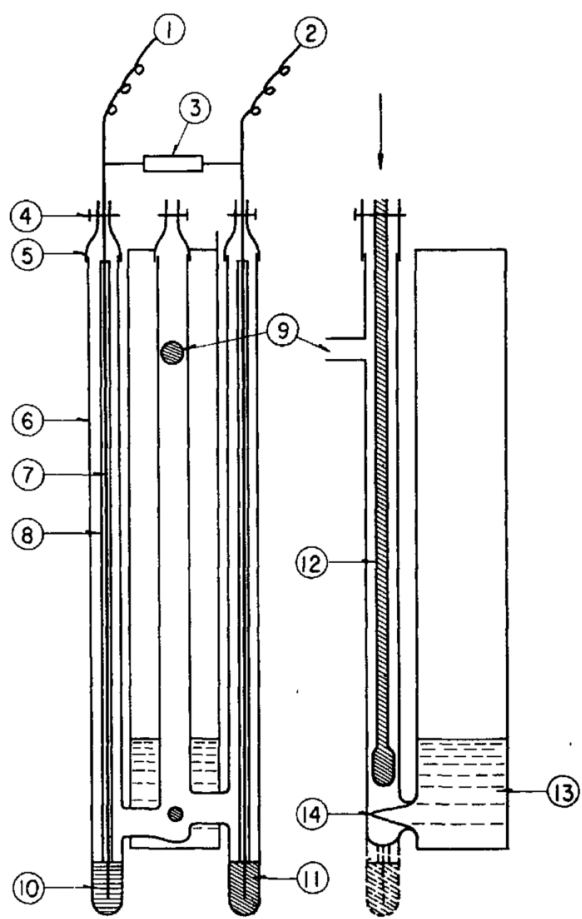

(1) Earth wire

(2) Signal wire

(3) Resistance

(4) Pinch cock

(5) Vinyl tube

(6) Hard glass

(7) Tungsten lead

Fig. 2 Cell for e.m.f. measurements. (A)

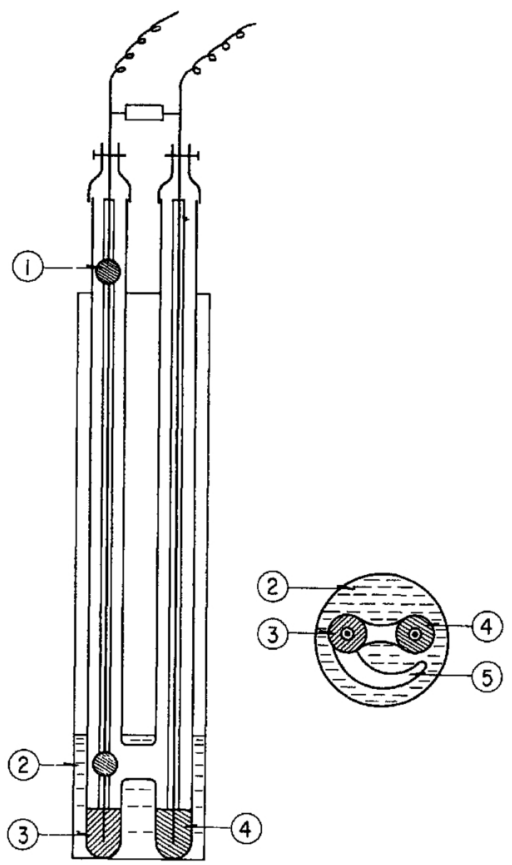

(1) $\mathrm{Ar}+\mathrm{H}_{2}$ gas inlet

(2) Electrolyte

(3) Pure metal electrode

(4) Alloy electrode

(5) Electrolyte inlet

Fig. 3 Cell for e.m.f. measurements. (B)
Iwasaki Communication Apparatus Co., LTD) with a camera was employed for the measurement of transient changes in electromotive force.

\section{Experimental Procedure}

The procedure for the measurements in the zinctin system with the A type cell is first described.

In the measurement of activities of the tin component, about $5 \mathrm{~g}$ of pure tin was placed in the pure metal electrode, while zinc and tin for alloying, weighed accurately in the approximately same volume as the pure electrode, were placed in the alloy electrode. Vinyl tubes were tightened by pinch cocks, the cell container was evacuated, and then a mixture of argon and hydrogen gases was introduced. After raising the temperature to $100^{\circ} \sim 200^{\circ} \mathrm{C}$, the cell was evacuated again, and the mixed gas was introduced. Subsequently, at about $400^{\circ} \mathrm{C}, 25 \mathrm{~g}$ of eutectic chlorides of $\mathrm{KCl}$ and $\mathrm{LiCl}$ containing 10 wt percent $\mathrm{SnCl}_{2}$ was put in the electrolyte tube. After melting the chlorides, the electrolyte was dehydrated by adding a small amount of $\mathrm{NH}_{4} \mathrm{Cl}$ and agitated sufficiently with a silica rod. The cell was held at $500^{\circ} \mathrm{C}$ for about 20 min before the eletromotive force was measured.

At the start of measurement the thermocouple was pulled out and the power was cut off. The spot on the oscilloscope due to the calibrated voltage was photographed immediately; the earth wire (outer wire of the coaxial cable) was connected to the lead of the pure tin electrode, and its spot (which is the standard of the electromotive force and is called the E spot for convenience) was photographed. Next, the signal wire (central wire of the coaxial cable) was connected to the lead of the alloy electrode, and the spot (called ES spot) was photographed if necessary. By breaking the electrolyte outlet with the stainless rod, the electrolyte was flown out to the pure metal electrode and then to the alloy electrode. The sweep curve thus produced on the oscilloscope was photographed. It must be considered as an inevitable consequence of the circumstances to cut the power as described later, but the error by temperature drop can be neglected if all photographs are taken within $1 \mathrm{~min}$.

In the measurements of the activities of the zinc component, the procedure is the same as mentioned above, except for a few modifications that the pure metal electrode is pure zinc and the electrolyte is eutectic chlorides of $\mathrm{KCl}$ and $\mathrm{LiCl}$ mixed with several percent zinc chloride instead of tin chloride.

In the moment the electrolyte touches with both electrodes, the cells are constituted as follows :

for the activity measurements of the zinc component,

$$
\left.\mathrm{Zn} \mid \mathrm{ZnCl}_{2} \text { (in } \mathrm{KCl}+\mathrm{LiCl}\right) \mid \mathrm{Zn}-\mathrm{Sn} \text {; }
$$

for the activity measurements of the tin component,

$$
\left.\mathrm{Sn} \mid \mathrm{SnCl}_{2} \text { (in } \mathrm{KCl}+\mathrm{LiCl}\right) \mid \mathrm{Sn}-\mathrm{Zn} \text {. }
$$

In the B-type cell, the electrolyte was weighed to be $60 \mathrm{~g}$, and the resistance of $10 \mathrm{~K} \Omega$ was selected to reduce the synchroscope spot movement as described 
later. The electrolyte was agitated by a vertical motion of the $H$ type tube and by a rotation of the electrolyte container. Except these modifications, the experimental procedure was the same as in the A-type cell. case the length of the spot is over $2 \mathrm{~mm}$ for the sensitivity of $5 \mathrm{mV} / \mathrm{cm}$, it is undesirable though the measurement is not necessarily difficult. From this result, the chief cause of humming is found to be the power source and the electric furnace. Accordingly, as the

Table 1 Experimental results on the hum in the synchroscope. $\left(\mathrm{Zn} / \mathrm{Zn}^{++} / \mathrm{Zn}-\mathrm{Sn}, N_{\mathrm{Zn}}=0.518\right)$

\begin{tabular}{|c|c|c|c|c|c|c|c|c|c|}
\hline \multirow{2}{*}{ No. } & \multicolumn{2}{|c|}{ Cell } & \multicolumn{2}{|c|}{ Power source } & \multicolumn{2}{|c|}{ Earth } & \multirow{2}{*}{$\begin{array}{c}\text { Resistance } \\
100 \mathrm{~K} \Omega\end{array}$} & \multicolumn{2}{|c|}{ Hum } \\
\hline & Earth wire & Signal wire & $\begin{array}{l}\text { Electric } \\
\text { furnace }\end{array}$ & $\begin{array}{c}\text { Furnace for } \\
\text { washing }\end{array}$ & $\begin{array}{c}\text { Furnace } \\
\text { tube }\end{array}$ & Angle & & $\begin{array}{l}\text { Length of } \\
\text { spot (mm) }\end{array}$ & $\begin{array}{l}\text { Sensitivity } \\
(\mathrm{mV} / \mathrm{cm})\end{array}$ \\
\hline $\begin{array}{r}1 \\
2 \\
3 \\
4 \\
5 \\
6 \\
7 \\
8 \\
9 \\
10 \\
11 \\
12 \\
13 \\
14 \\
15 \\
16 \\
17 \\
18\end{array}$ & $\begin{array}{l}x \\
x \\
x \\
x \\
x \\
x \\
0 \\
0 \\
0 \\
8 \\
8 \\
8 \\
0 \\
0 \\
0\end{array}$ & $\begin{array}{l}x \\
x \\
x \\
x \\
x \\
x \\
x \\
x \\
x \\
x \\
0 \\
x \\
x \\
0 \\
0 \\
0 \\
0\end{array}$ & $\begin{array}{l}x \\
x \\
0 \\
0 \\
x \\
x\end{array}$ & $\begin{array}{l}0 \\
x \\
x \\
0 \\
x \\
x \\
x\end{array}$ & $\stackrel{x}{8}$ & $\begin{array}{l}0 \\
x \\
x \\
x \\
x \\
x \\
\bigcirc \\
\bigcirc\end{array}$ & $\begin{array}{l}x \\
x \\
x \\
x \\
x \\
x \\
x \\
x \\
x \\
x \\
x \\
x \\
0 \\
0 \\
0 \\
0 \\
0\end{array}$ & $\begin{array}{r}1.2 \\
10.0 \\
14.0 \\
4.0 \\
1.2 \\
8.0 \\
4.0 \\
2.0 \\
1.2 \\
3.8 \\
4.0 \\
13.0 \\
4.0 \\
16.0 \\
2.0 \\
1.2 \\
15.0 \\
22.0\end{array}$ & 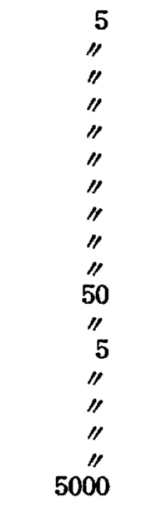 \\
\hline
\end{tabular}

\section{Problems in Measurements}

\section{Humming from other electrical systems}

One of the experimental difficulties was the interference of hum in the synchroscope. In the present method the pure metal and alloy electrodes are electrically afloat, so that humming is a problem of special importance.

It seems reasonable to consider that humming is necessarily introduced in the synchroscope from other electrical equipment and systems located at the laboratory. The synchroscope is greatly influenced by humming, for example, when a high frequency induction furnace is operated nearby. Since humming lengthens the synchroscope spot vertically, the measurements are found to be difficult unless it is minimized. For diminishing hum in the arrangement shown in Fig. 1, the following countermeasures may be employed.

(1) Earthing of the angle frame for the apparatus.

(2) Earthing of the stainless pipe in the electric furnace.

(3) Insertion of a large resistance $(10$ or $100 \mathrm{~K} \Omega$ ) between the signal and earth wires.

(4) Momentary cut-off of the power during the measurement.

The effectiveness of these countermeasure for the elimination of humming is given in Table 1 . The marks $\bigcirc$ and $x$ denote the cases where the power source, earth lines or resistance is connected with the measuring apparatus and vice versa, respectively. It is evident from Table 1 that humming can be made negligibly small by means of careful experimental technique and design.

The extent of humming was represented by the length of a synchroscope spot in each sensitivity. In primary countermeasure, the earthing of the furnace pipe is required. Further, the power must be momentarily cut off to reduce hum during the measurements. It is also found that humming can be diminished by the insertion of resistance between the signal and earth wires. Of course, since the measured electromotive force is influenced when the resistance inserted is too small, a fairly large resistance is needed. But, in this case, a small resistance within the limit where the error to the electromotive force can be neglected is desired. 100 or $10 \mathrm{~K} \Omega$ was selected as the resistance which is expected to show no effect on the electromotive force.

It is also desirable that the thermocouple is taken out as it induces humming and the use of other equipment in the laboratory or its surroundings is avoided in the measurement.

\section{The movement of synchroscope spots}

Another serious problem is that the spot moves at elevated temperatures. When the pure metal and alloy electrodes are electrically afloat as in the case of the A type cell, the electromotive force cannot be considered to arise. Therefore, both $\mathrm{E}$ and $\mathrm{ES}$ spots must be in the same position. However, connecting the signal and earth wires to both electrode leads after raising temperature, the spot moves from the position of the $\mathrm{E}$ spot. That is, a certain electromotive force may be considered to arise between the two electrodes. In the A-type cell, its value is $2 \mathrm{mV}$ at least, but if the cell holder made of refractories is wetted with chlorides even in a slight degree, the spot may be moved over $150 \mathrm{mV}$. Even if the spot moves in such a manner, no error was introduced to the measurement value because this movement occur's by the electromotive force arisen through the glass container and the cell of this condition has a large resistance 
compared with the value when the electrolyte touches with both electrodes. However, it is desired that the electromotive force is reduced as small as possible, since its presence from the beginning make necessary measurements difficult. In the A-type cell, a clean holder must be employed and the remaining electromotive force can be eliminated to some extent by the insertion of resistance $(10 \sim 100 \mathrm{~K} \Omega)$ between the earth and signal wires. The spot in the B-type cell may move considerably because both electrodes are immersed in the electrolyte. Therefore, there is no choice but to insert the resistance, and the use of a smaller resistance of $10 \mathrm{~K} \Omega$ is agreeable which does not affect the measured values.

\section{Sweep Curve}

Fig. 4 illustrates the sweep curves in the measurements of activities of the zinc component. Since, in
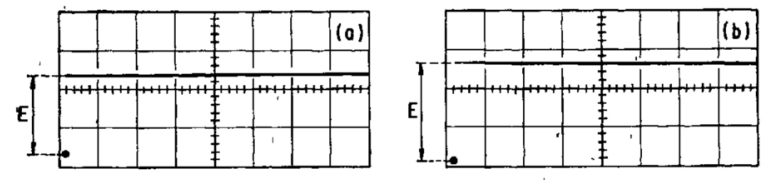

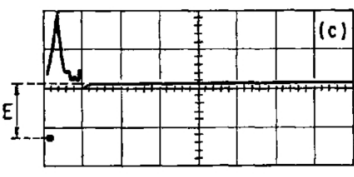

(a) $\mathrm{N}_{\mathrm{Zn}}=0.0245,50 \mathrm{mV} / \mathrm{cm}$ (b) $\mathrm{N}_{\mathrm{Zn}_{\mathrm{n}}}=0.0113,50 \mathrm{mV} / \mathrm{cm}$

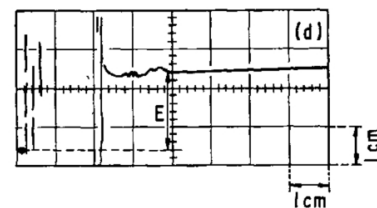

(c) $\mathrm{N}_{\mathrm{Zn}}=0.254,20 \mathrm{mV} / \mathrm{cm}$ (d) $\mathrm{N}_{\mathrm{Zn}}=0.800,2 \mathrm{mV} / \mathrm{cm}$ component. (Sweep speed $0.2 \mathrm{sec} / \mathrm{cm}$ )

this case, the substitution reaction between the electrolyte and the alloy is negligible, the spots arrive at an activity potential points as soon as the electrolyte touches with the electrodes, and after that no changes in potential were generally observed.

Figs.4 (a) to 4 (d) illustrate the typical sweep curves. Fig. 4 (a) illustrates the curve, in which the spot rose in the moment when the electrolyte touches with the alloy electrode and moved to the activity potential point at once. Fig. $4(\mathrm{~d})$ presumably rose in breaking the electrolyte outlet. Figs. 4 (b) and 4 (c) are curves intermediate between Figs. 4 (a) and $4(\mathrm{~d})$. Prior to the stage at which the electrolyte touches with the electrodes, it is found that the sweep curves are not always similar.

Examples of the sweep curves in the activity measurements of the tin component are presented in Figs. 5 and 6 . By the reaction when the electrolyte touches with the alloy electrode, the sweep curves in these cases are apt to be complicated.

Fig. 5 shows a typical illustration of the photograph which was taken in particularly small sensitivity for the purpose of obtaining the entire picture of the sweep curves. As soon as the electrolyte touches with the alloy electrode, the spot moves to the activity potential point and then runs downwards by the momentary reaction occurring between $\mathrm{SnCl}_{2}$ in the electrolyte and zinc in the alloy. The alloy electrode is positive in the activity measurement so that the spot moves upward and then runs downward as the alloy electrode becomes negative by the reaction. It is

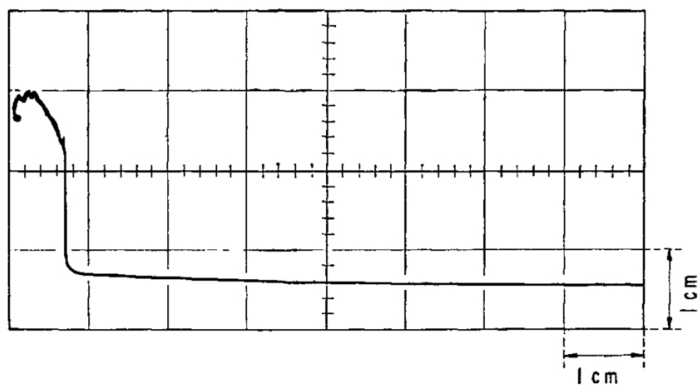

Fig. 5 Sweep curve in the activity measurement for tin component. $\left(\mathrm{N}_{\mathrm{Sn}}=0.267,200 \mathrm{mV} / \mathrm{cm}, 0.2 \mathrm{sec} / \mathrm{cm}\right)$
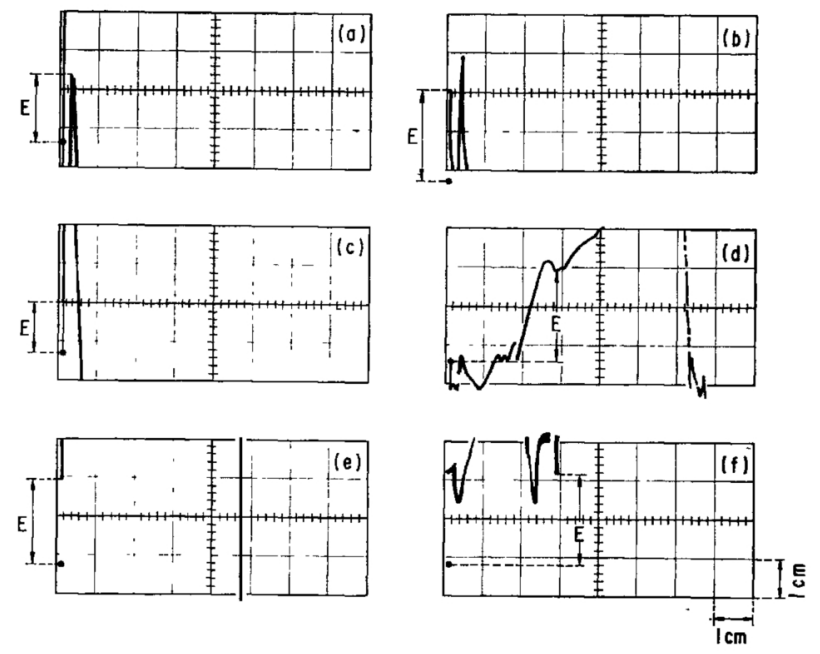

(a) $\mathrm{N}_{\mathrm{Sn}}=0.688,5 \mathrm{mV} / \mathrm{cm}$

(b) $\mathrm{N}_{\mathrm{Sn}}=0.271,10 \mathrm{mV} / \mathrm{cm}$

(c) $\mathrm{N}_{\mathrm{Sn}}=0.192,20 \mathrm{mV} / \mathrm{cm}$

(d) $\mathrm{N}_{\mathrm{Sn}}=0.101,20 \mathrm{mV} / \mathrm{cm}$

(e) $\mathrm{N}_{\mathrm{Sn}}=0.300,10 \mathrm{mV} / \mathrm{cm}$

(f) $\mathrm{N}_{\mathrm{Sn}}=0.0189,50 \mathrm{mV} / \mathrm{cm}$

Fig. 6 Sweep curves in the activity measurements for tin component. (Sweep speed, $0.2 \mathrm{sec} / \mathrm{cm}$ )

also observed that the electromotive force after the reaction is not so variable.

Figs. $6(\mathrm{a})$ to $6(\mathrm{~d})$ were obtained by the measurements based on the $E$ spot, and Figs. $6(\mathrm{e})$ and $6(\mathrm{f})$ on the ES spot. As shown in Figs. 6(a) to 6(d) the curves are known to change depending on the concentration or sensitivity. At a higher concentration, the sweep curve becomes more Fig. 6 (a) type; at a lower concentration, it becomes more Fig. 6 (d) type. Figs. 6 (b) and $6(\mathrm{c})$ are the intermediate types. Figs. $6(\mathrm{e})$ and 6 (f) are the cases without resistance and were photographed on the ES spot because of the large spot movement.

\section{Measured Activities}

The $\mathrm{Zn}$-Sn system was taken up as an example and its activities were measured. The measured values of electromotive force are summarized in Table 2.

The A-type cell was employed in all runs with the exception of one run, and the sensitivities were changed depending on the electromotive force values 
measured. Although the greater part of the runs were measured on the basis of the E spot, but the runs without resistance were measured on the ES spot because of the large spot movement.

The activities of zinc and tin were calculated from

Table 2 Electromotive force values in the $\mathrm{Zn}-\mathrm{Sn}$ system. (Sweep speed $0.2 \mathrm{sec} / \mathrm{cm}$ )

\begin{tabular}{l|c|c|c|c|c}
\hline \hline $\mathrm{N}_{\mathrm{Zn}}$ & $\begin{array}{c}\mathrm{E} \\
(\mathrm{mV})\end{array}$ & $\begin{array}{c}\text { Sensitivity } \\
(\mathrm{mV} / \mathrm{cm})\end{array}$ & $\mathrm{N}_{\mathrm{Sn}}$ & $\begin{array}{c}\mathrm{E} \\
(\mathrm{mV})\end{array}$ & $\begin{array}{c}\text { Sensitivity } \\
(\mathrm{mV} / \mathrm{cm})\end{array}$ \\
\hline 0.0113 & 128.0 & 50 & 0.0386 & 104.1 & 50 \\
0.0245 & 102.7 & 50 & 0.101 & 49.3 & 20 \\
0.0485 & 79.5 & 50 & 0.147 & 33.5 & 20 \\
0.0771 & 64.7 & 20 & 0.192 & 28.9 & 20 \\
0.167 & 40.8 & 20 & 0.195 & 28.1 & 10 \\
0.254 & 28.9 & 20 & $0.271^{*}$ & 25.1 & 10 \\
0.376 & 18.3 & 10 & 0.340 & 22.4 & 20 \\
0.518 & 12.2 & 5 & 0.496 & 16.1 & 20 \\
0.563 & 10.3 & 5 & 0.611 & 12.5 & 5 \\
0.663 & 7.34 & 2 & 0.688 & 9.47 & 5 \\
0.800 & 4.26 & 2 & 0.798 & 6.33 & 2 \\
& & & $0.0189^{* *}$ & 129.0 & 50 \\
& & & $0.300^{* *}$ & 23.8 & 10 \\
\hline
\end{tabular}

* B-type cell ** Based on earth-signal spot, no resistance

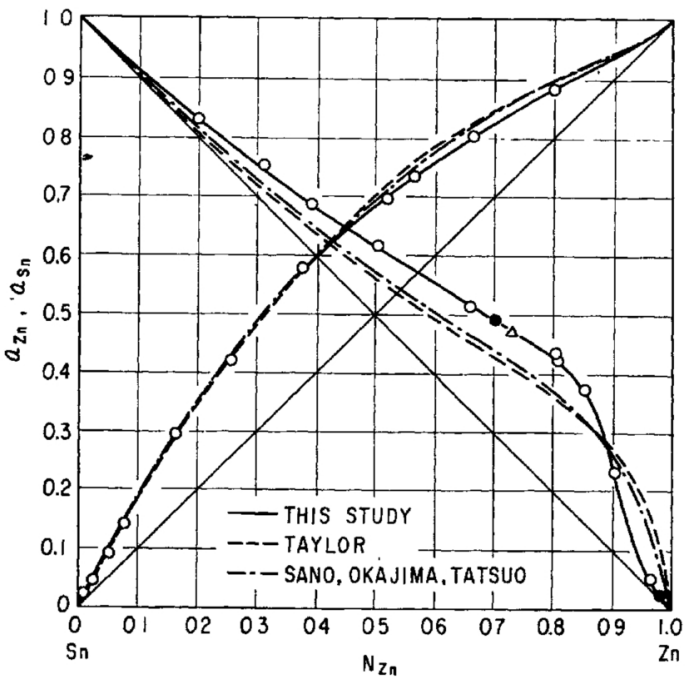

Fig. 7 Activities of zinc and tin in the $\mathrm{Zn}$-Sn alloys. $\left(500^{\circ} \mathrm{C}\right)$ Symbols, $\triangle$ B-type cell, Based on ES spot

the electromotive force values obtained by virtue of Eqs. 3 and 5 . Fig. 7 shows the activities of both components. The results of the present measurements are compared with the data of Taylor ${ }^{(3)}$ and Sano et al. (4). The present results of the activities of zinc agree fairly well with the values obtained by the usual method. However, the agreement in the activities of tin is poor, probably due to the fact that the values obtained by the usual method are those calculated by Gibbs-Duhem's equation.

The results which employed the B-type cell and were based on the ES spot were in good agreement with the other values. Accordingly, the B-type cell is found to be similarly useful as is the case with the A-type cell. On the other hand, it seems difficult at

(3) N. W. Taylor: J. Amer. Chem. Soc., 45 (1923), 2865.

(4) K. Sano, K. Okajima and S. Tatsuo: Mem. Fac. Eng., Nagoya Univ., 5 (1953), 299.

(5) W. M. Boorstein and R. D. Pehlke: J. Electrochem. Soc., 111 (1964), 1269. the present time to clarify the reason why the results based on the ES spot agree with that by the E spot. However, from the fact that both results agree with each other in the present experiment, it is concluded empirically that both spots can be taken as standards.

In the measurements of $a_{\mathrm{Zn}}$, in general, the electromotive force based on the $\mathrm{E}$ spot can be easily obtained, but in this case, a few values based on the ES spot were also obtained and both values based on $\mathrm{E}$ and $\mathrm{ES}$ spots were found to be in good agreement with each other.

This method can be employed not only for the activity measurements of both components in the binary alloy, but also for study of the dilute solution. Recently, Pehlke et al. ${ }^{(5) \sim(10)}$ have reported the results of a number of investigations on the dilute solutions of low melting alloys. These studies were carried out using the usual electromotive force method under the condition the electrolyte is always touching with both electrodes. Accordingly, errors caused by the substitution reaction between the electrolyte and the alloy electrode and by the dissolution of metal in the electrolyte pose a problem. As the more the solution dilutes, the larger the errors, there is a limit in the concentration range to be measured, and satisfactory results have been not obtained below the mole fraction of solute, 0.01 .

The activities of zinc in the dilute solution by the present measurements are compared in Fig. 8 with the data of Pehlke et al. ${ }^{(9)}$, in which the broken line represents Raoult's law. Both activities of zinc follow Henry's law at concentrations up to 0.1 mole fraction

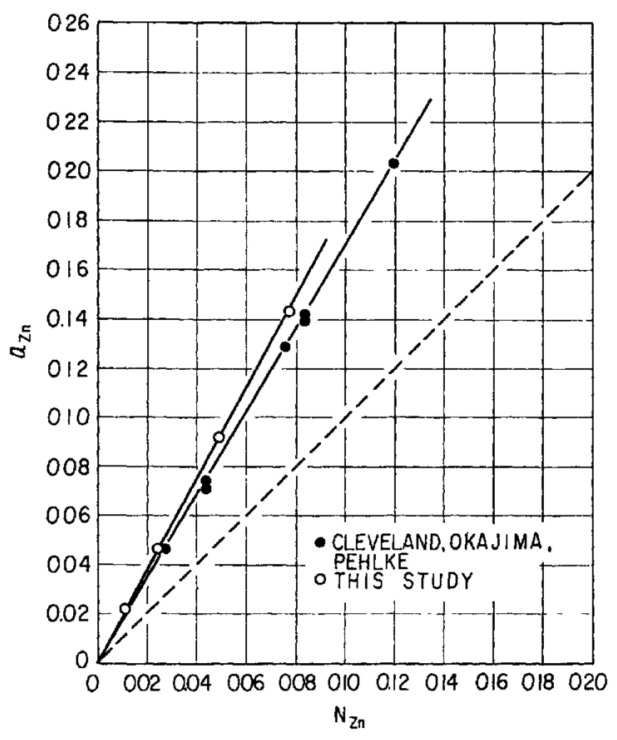

Fig. 8 Activities of zinc in the dilute $\mathrm{Zn}-\mathrm{Sn}$ alloys. $\left(500^{\circ} \mathrm{C}\right)$

(6) K. Okajima and R. D. Pehlke: Trans. Met. Soc. AIME, 230 (1964), 1731.

(7) J. V.Gluck and R.D. Pehlke: Trans. Met. Soc. AIME, 233 (1.965), 233.

(8) K. Okajima and R. D. Pehlke : J. Japan Inst. Metals, 29 (1965), 961.

(9) S. T. Cleveland, K. Okajima and R. D. Pehlke : J. Phys. Chem., 69 (1965), 4085.

(10) J. V. Gluck and R. D. Pehlke: Trans. Met. Soc. AIME, 239 $(1967), 36$. 
of zinc, but the activity values by this method are high compared with the data of Pehlke et al.. This discrepancy probably resulted from the difference in the experimental method.

As to the discrepancy between the activities of tin

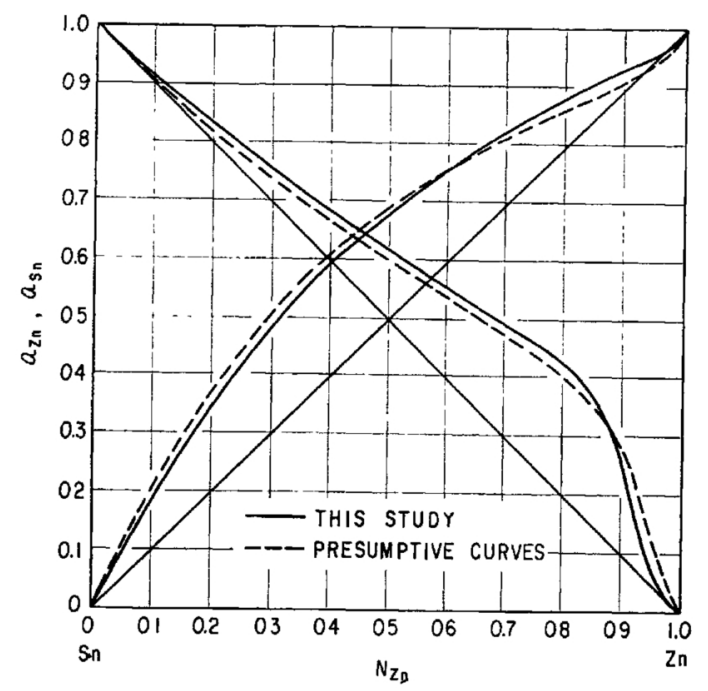

Fig. 9 Activities obtained by the measurements and GibbsDuhem integration in the $\mathrm{Zn}-\mathrm{Sn}$ system. $\left(500^{\circ} \mathrm{C}\right)$

by the present method and Gibbs-Duhem integration, it seems risky to draw a hasty conclusion from only one example of the $\mathrm{Zn}-\mathrm{Sn}$ system. But the results of the present study are discussed in the next section.

The electromotive force method is one of the most precise methods for determining the activities at relatively low temperatures. However, generally speak- ing, a method will be attended with some error whatever high accuracy it may be. Accordingly, if the measured value of $a_{\mathrm{zn}}$ has some error peculiar to the cell, the $a_{\mathrm{Sn}}$ value calculated on the basis of $a_{\mathrm{Zn}}$ regarding as the absolutely correct value will deviate as much from the true value. In the results of the present study, if the some error peculiar to the cell is considered, the error must be considered not only for $a_{\mathrm{Zn}}$ but also for $a_{\mathrm{Sn}}$. From this point of view, the $a_{\mathrm{Zn}}$ curve was decided properly and the $a_{\mathrm{Sn}}$ curve was calculated from the curve using the Gibbs-Duhem's equation. The result is shown in Fig. 9. Since both curves closely resemble with each other, it is assumed that the measured activities of both components by this method are not contradictory to the Gibbs-Duhem integration. However, since this problem is very important, it must be examined by further experiments in the future.

\section{Summary}

The activities can be measured, regardless of the reaction between the electrolyte and the alloy electrode, by the touch instant electromotive force method. That is, the activities of the more noble component in the binary molten alloys which cannot be measured by the usual method can be measured by the method.

In the measurements, utmost care should be given to minimize humming in the synchroscope. It was found that the activities of both components in the binary alloy are measured with good accuracy. 